\title{
Elderly Welfare System and Role of Dental Hygienists in Korea and Japan
}

\author{
Myung-Jin Lee, Do-Kyeong $\mathrm{Kim}^{1,2}$, Soo-Jeong Hwang ${ }^{2}$, and Sang-Hwan $\mathrm{Oh}^{2, \dagger}$ \\ Department and Research Institute of Dental Biomaterials and Bioengineering, Yonsei University College of Dentistry, \\ Seoul 03722, \\ ${ }^{1}$ Oral Cancer Research Institute and Department of Oral Pathology, Yonsei University College of Dentistry, Seoul 03722 , \\ ${ }^{2}$ Department of Dental Hygiene, College of Medical Science, Konyang University, Daejeon 35365, Korea
}

\begin{abstract}
In accordance with the aged society, oral health care for the elderly is considered important to maintain general health. Although the role of dental hygienists is essential for proper health management of the oral cavity, research on the care system for the elderly people's oral health and on the role of dental hygienists in the field of elderly welfare is still insufficient. Hence, the aim of this study is to investigate the status of Korean elderly welfare system and dental hygienists by comparing them with those in Japan, a precedent of aged society. First, we compared and investigated the Japanese long-term insurance system, which provides an institutional basis for a long-term care system for the elderly in Korea. Second, the elderly welfare law and care system, focusing on oral care, were examined. Lastly, in elderly care, we analyzed the distinctions between Korea and Japan regarding dental hygienists' role and scope of work. Taken together, as a precedent of aged society, Japan has shown well-specialized and systematic welfare for the elderly compared with Korea. With the development of the welfare system for the elderly in Japan, the role and the work scope of dental hygienists have been expanded to improve quality of life of elderly people, as a key professional for elderly oral care. Therefore, we should perceive the need for improvement of long-term care insurance and the expansion of dental hygienists' work in Korea. In conclusion, these results could be used as basic data for improving the elderly welfare system and developing dental hygienists in Korea.
\end{abstract}

Key Words: Aged, Dental hygienists, Long-term care, Oral health

\section{Introduction}

According to the classification of population structural change of the United Nations (UN), a country is classified as an aging society if the ratio of persons aged 65 years or older is over $7 \%$ of the entire population, an aged society if the ratio is over $14 \%$, and a super-aged society if the ratio is over $20 \%^{1)}$.

Korea transitioned to an aging society, with persons aged 65 years or older accounting for $7.1 \%$ of its population in 2000 . The ratio increased to $10.2 \%$ ( $\mathrm{n}=$ $5,069,273)$ in 2008, and $12.7 \%(\mathrm{n}=6,520,607)$ in 2014 , and has been increasing consistently. The National Statistical Office anticipated that Korea would become an aged society by 2018, and a super-aged society by 2026 . However, Korea transformed into an aged society around the end of August in 2017, with the ratio of persons aged 65 years or older stood at $14.02 \%(n=7,527,288)$; it is expected to become a super-aged society in one to two years earlier than expected. The transition to an aged society started in 1995 at the regional level; around 80 cities became super-aged societies in $2010^{2}$. Of all the member countries of the Organisation for Economic Co-operation and Development (OECD), Korea has undergone changes in the population structure at the fastest rate. France took 115 years; the United States, 72 years; and Japan, which underwent rapid population aging, 24 years, to transform from an aging into an aged 
society ${ }^{1)}$. By contrast, Korea become an aged society in only 17 years, is expected to surpass Japan in the size of elderly population, and will have the highest ratio of elderly persons by $2065^{3)}$.

Elderly people are prone to experience social isolation and financial difficulties due to loneliness, loss of roles, and poverty. They are also vulnerable to diseases in consequence of the shortage of workforce in the medical and health fields, and their worsening health functions. Systemic diseases or health conditions have been found to be closely associated with oral health conditions ${ }^{4,5}$. Although the importance of systemic oral health management of elderly people for healthy living has been emphasized, according to the status on general health checkup comprehensive assessment of dental examination and measures (National Statistical Office, 2014 to 2016) ${ }^{6}$, only $2.04 \%$ ( $n=9,939)$ of 488,278 subjects had healthy oral conditions. Meanwhile, 29.38\% ( $n=143,454)$ required dietary consultation, expert oral hygiene management, and periodontal management; $21.58 \%(n=105,365)$ required a visit to a dental clinic because of the possibility of developing dental caries and periodontal diseases; and $47.01 \%(n=229,520)$ required immediate care for dental caries and periodontal diseases.

Dental hygienists play crucial roles in resolving these problems. With the reform of the Elderly Welfare Act (2016), dentists can now work in part-time at long-term care facilities for the elderly to provide professional oral hygiene care in Korea. However, policies on the obligatory designation and part-time employment of dental hygienists, who can provide oral hygiene care for elderly residents in long-term care facilities, have not been established ${ }^{7,8)}$.

Therefore, this study aimed to compare the elderly oral health management systems and the role of dental hygienists between Korea and Japan, which underwent population aging before Korea, to explore ways to expand the range of tasks and social roles of dental hygienists in the aged Korean society.

\section{Materials and Methods}

This study used websites of the organizations and institutions in Japan and Korea (Table 1). For Korea, statistics released by the Korean Statistical Information Service, and articles and data available on the Korean Dental Hygienists Association (KDHA) website were analyzed. For Japan, statistics released by the Ministry of Health, Labour and Welfare, and data from the Japan Dental Hygienists' Association were analyzed. We visited a university hospital and a long-term care facility located in Hiroshima for six months, from September 2017 to February 2018, to collect data on the current situations in Japan, and received advice from Professor Masaru Sugiyama (杉山 勝) from the Department of Oral Health Sciences at Hiroshima University. The collected data were used to investigate long-term care system for the elderly centered around elderly welfare system and oral health management, and the status and role of dental hygienists in long-term care facilities.

\section{Results}

\section{Changes in long-term care systems for the elderly in Korea and Japan}

Because of changes in social environments and increase in medical costs for the elderly, as a result of the rapid population aging, the need for a long-term care system for the elderly has been suggested. Since the emergence of silver industries in the 1990s, private businesses, including civilians, can participate in elderly welfare industries; moreover, home welfare became activated after the introduction of a long-term care system for the elderly in $2001^{9)}$. Since the introduction of a long-term care insurance system in 2008, insurance services, including nursing, physical activity, and housekeeping activity services, were provided for elderly persons suffering from geriatric

Table 1. Sources of Information

\begin{tabular}{ll}
\hline \multicolumn{1}{c}{ Group } & \multicolumn{1}{c}{ Sources of information } \\
\hline Korean Statistical & http://kosis.kr/index/index.do \\
Information Service & \\
Korean Dental & http://www.kdha.or.kr/ \\
Hygienists Association & \\
Japan Dental & http://www.jdha.or.jp/index.aspx \\
Hygienists' Association & \\
Ministry of Health, & http://www.mhlw.go.jp/index.shtml \\
Labour and Welfare & \\
\hline
\end{tabular}


diseases, such as Alzheimer's and cerebrovascular diseases. However, owing to lack of oral care guidelines, oral health and hygiene examinations for the elderly could not be performed properly; thus, dental hygienists could not perform their roles fully ${ }^{10}$. However, with the reform of the enforcement regulations of the Elderly Welfare Act of 2016, part-time participation of dentists was permitted to reinforce medical services provided in long-term care facilities for the elderly (Fig. 1). Thus, dentists, who are experts in oral health care, can now provide oral health care services in long-term care facilities for the elderly ${ }^{11)}$.

In Japan, an elderly welfare system developed at a fast rate in response to the rapid population aging. Japan was the first country to enact the Elderly Welfare Act as an independent single law in 1963, began providing free medical services for the elderly in 1972, planned longterm measures by enacting the Elderly Health act in 1982, and initiated the long-term care insurance system in the $2000 \mathrm{~s}^{12)}$. In the long-term care insurance system, individuals with difficulty performing activities of daily life and limited social activities pay their insurance premiums in advance for future care and eventually receive benefits ${ }^{13)}$. The purpose of this system is to provide individuals, who need assistance in daily activities of life due to diseases caused by aging, with training, nursing, long-term care, and other medical care that are suitable for them according to the individuals' abilities to pay, thereby helping them live an independent life ${ }^{14)}$. The ultimate goal is to improve quality medical services and welfare for the nation ${ }^{14)}$. Another goal is to maintain the dignity of the elderly, which was guaranteed in the revision in $2005^{14)}$. Based on these principles, the long-term insurance system was supposed to review the overall situation of the system every five years in accordance with the regulations ${ }^{15)}$. The first revision in 2005 included the shift of insurance system from being life insurance-focused to preventionfocused (Fig. 1). Hence, the amendments were related to facility service benefits, establishment in new service systems, improvement of quality of services, and revision of charging standard and system operation ${ }^{12)}$.

\section{Oral health management status of the elderly in Korea and Japan}

Persons aged 60 years or older account for $33.4 \%$ of all one-person households; meaning, a third of one-person households comprises those in the advanced age. Many of them have low income and are impoverished and need welfare policies, such as residential care. The advances in medical technology have led to an increased number of elderly persons admitted to hospitals for long-term hospitalization and of those with chronic diseases. Moreover, the number of elderly persons who move to long-term care facilities has increased, and is expected to continue soaring. Although elderly people receive longterm hospitalization, or live in a long-term care facility, they can be exposed directly and indirectly to negative factors that hinder their oral health maintenance ${ }^{16)}$. Persons of advanced age can exhibit symptoms, such as weakened masticatory ability, reduced number of mastication, and impaired salivary gland functions. Moreover, owing to lack of oral health care activities, systemic diseases, and side effects of medications, the amount of saliva secretion

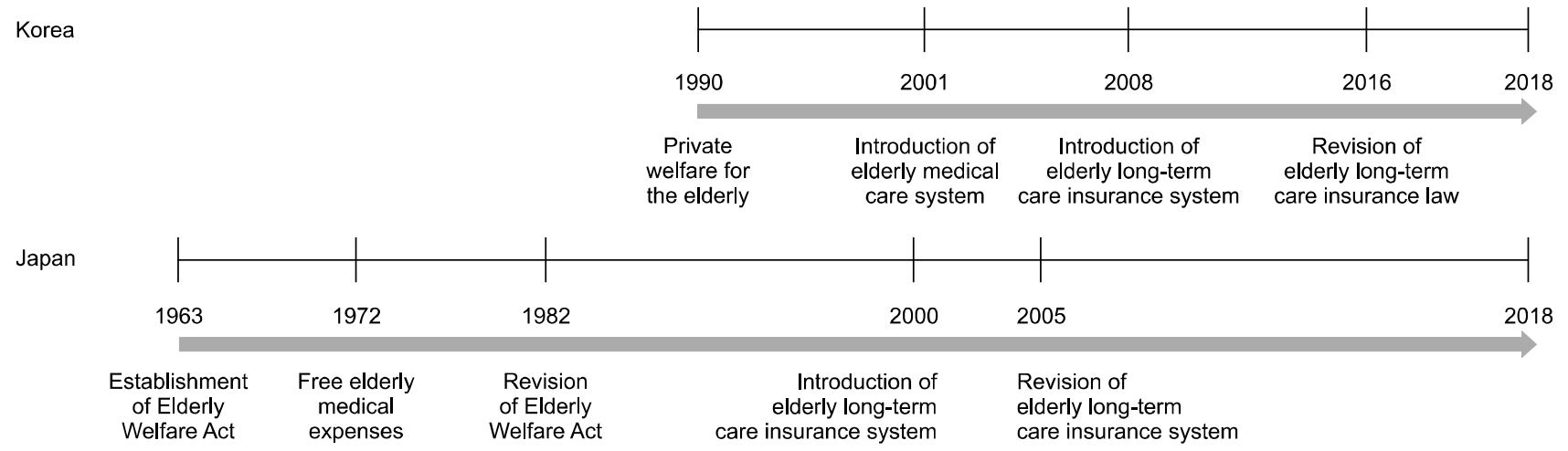

Fig. 1. History of elderly care system in Korea and Japan. 
may decrease, leading to oral health problems ${ }^{17,18)}$. A previous study reported that massaging the muscles of the oral cavity and conducting mouth exercises can promote saliva secretion effectively, and that oral health can be improved by controlling the amount of saliva and stimulating mastication and sense of taste through massage ${ }^{19,20)}$. Elderly persons experience difficulty in ingestion as their muscles related to deglutition deteriorate with age, impairing the masticatory function and deglutition. Malnutrition that continues for a long time not only accelerates aging but also causes chronic diseases and worsen the health; thus, it has serious significance in these people. Dietary ingestion is a basic requirement for improving and maintaining

Table 2. Elderly Care Facilities in Korea and Japan

\begin{tabular}{|c|c|c|}
\hline Country & Facility & $\begin{array}{c}\text { Number of } \\
\text { facility/person }\end{array}$ \\
\hline \multirow[t]{10}{*}{ Korea } & Medical welfare elderly facility & \\
\hline & Care facility & $3,137 / 150,395$ \\
\hline & Congregate housing & $2,050 / 17,961$ \\
\hline & Home care elderly facility & \\
\hline & Home care service & $11,072 /-$ \\
\hline & Home bating service & $8,957 /-$ \\
\hline & Visiting nursing service & $598 /-$ \\
\hline & Day and night care & $2,410 / 52,666$ \\
\hline & Short-term care & $267 / 2,551$ \\
\hline & Welfare medical device & $1,823 /-$ \\
\hline \multirow[t]{11}{*}{ Japan $^{\mathrm{a}}$} & $\begin{array}{l}\text { Nursing care prevention service } \\
\text { office }\end{array}$ & \\
\hline & $\begin{array}{l}\text { Nursing care prevention visit } \\
\text { nursing care }\end{array}$ & $34,113 /-$ \\
\hline & $\begin{array}{l}\text { Nursing care prevention school } \\
\text { (通所) }\end{array}$ & $41,448 /-$ \\
\hline & Care service office & \\
\hline & Visiting nursing care & $35,013 /-^{\mathrm{c}}$ \\
\hline & Nursing care school (通所) ${ }^{\mathrm{b}}$ & $23,038 /-$ \\
\hline & Community-based nursing care & $21,063 /-^{c}$ \\
\hline & Long-term care insurance facility & \\
\hline & $\begin{array}{l}\text { Long-term care old-welfare } \\
\text { institution }\end{array}$ & $7,705 / 530,280$ \\
\hline & $\begin{array}{l}\text { Long-term care geriatric health } \\
\text { facility }\end{array}$ & $4,241 / 370,366$ \\
\hline & Medical care health care facility & $1,324 / 59,106$ \\
\hline
\end{tabular}

${ }^{\text {a }}$ Survey on health care service facilities and business establishments in Ministry of Health, Labour and Welfare (MHLW, 2016). ${ }^{\mathrm{b}}$ Social welfare facilities, such as senior citizen welfare center, welfare center for the disabled (career guidance training, care, education, rehabilitation, etc).

${ }^{\mathrm{c}}$ The users of community-based care $(390,000)$ and the users of visiting nursing care $(3,820,000)$ (MHLW, 2015). health. Meanwhile, oral health management is essential for improving the quality of life of the elderly population ${ }^{21)}$. However, oral health management of the elderly in longterm care facilities is reported to be a relatively low priority in Korea ${ }^{22)}$. Although disease detection and treatment are important, disease prevention and lifestyle improvement have a significant influence on improving the health of an elderly individual. To provide consistent and systematic oral health care, an oral health management system must be introduced by a national policy. Welfare systems, such as residential care in which dentists and dental hygienists visit their patients to provide oral health care at the patients' home, hospital, and long-term care facility care, oral health prevention projects, and oral hygiene product benefits are also needed.

Dentists who examined the elderly in Japan divided the residents of a long-term care facility into an oral hygiene care and a self-care group, and followed up these residents for two years to investigate if lack of oral hygiene care is associated with fever, pneumonia, and deaths due to pneumonia. The incidence of fever and pneumonia and the mortality rate due to pneumonia were reduced

Table 3. Status of Professionals in Long-Term Care Facilities in Korea and Japan

\begin{tabular}{lcr}
\hline \multicolumn{1}{c}{ Professional workforce } & Korea & Japan $^{\mathrm{a}}$ \\
\hline Social worker & 0.96 & 1.0 \\
Doctor & $0.32^{\mathrm{b}}$ & 4.0 \\
Nurse & 0.29 & 14.0 \\
Dental hygienist & $0^{\mathrm{c}}$ & 0.1 \\
Physical (occupational) therapist & 0.35 & 5.9 \\
Care worker (Korea) or long-term & 11.67 & 71.5 \\
$\quad$ care staff (Japan) & d & \\
Nutritionist & 0.21 & 3.4 \\
Nursing assistant & 1.36 & 12.6 \\
\hline
\end{tabular}

The table excludes the number of professional staff working on home-care facilities (visiting home-care services) (Korean Statistical Information Service [KOSIS], 2016) (Ministry of Health, Labour and Welfare, 2016).

${ }^{a}$ In Japan, there are many subspecialized professional workers (speech therapists: 0.7, osteopathists [bonesetter]: 0.1, acupressurists: 0.1 , consultants [for nursing, living and support]: 2.9 , etc.). ${ }^{\mathrm{b}}$ Including dentists and visiting doctors (non-regular doctor).

${ }^{\mathrm{c}}$ The elderly medical welfare facility (0), and the elderly homecare facility (5; Seoul: 3, Daegu: 1, Chungcheongbuk-do Cheongju: 1) (KOSIS, 2016).

${ }^{\mathrm{d}}$ Visiting care staff, including Japanese care worker and homehelper, etc. 
significantly in the oral hygiene care group. With this finding, the importance of oral hygiene care was re-emphasized. The opinions of many health professionals and providers of nursing services also changed ${ }^{23)}$. This finding prompted dental professionals to manage the oral health of patients in long-term care facilities and general hospitals $^{23)}$.

\section{Comparison of the role of dental hygienists in long-term care facilities in Korea and Japan}

\section{1) Status and role of dental hygienists in Korean long-term care facilities}

In Korea, the numbers of long-term care facilities for the elderly and community care centers for residential care and nursing services were $3,137,11,072$, and 598, respectively; 223,573 elderly persons use long-term care facilities (Table 2$)^{24-27)}$. However, the number of dental hygienists who can provide professional oral hygiene care in these long-term care facilities was 0 per facility (Table 3$)^{28)}$. According to the data released by the National Statistical Office in 2016, the number of dental hygienists deployed in a long-term care facility for the elderly was 0 , and to a community care center for the elderly was five (three in Seoul Metropolitan City, one in Daegu Metropolitan City, and one in Cheongju, North Chungcheong Province). The number of dentists was not investigated as dentists were categorized as doctors. Investigating the dentists independently was also difficult. Because of the lack of dental professionals at present, providing professional oral health care for elderly residents in long-term care facilities and community care centers is a challenge.

The KDHA considered such situation and implemented the first professional dental hygienist training course for the improvement of the elderly's oral health in 2008. The association also implemented educational programs for the elderly and patients' legal guardians. These programs included training for dental plaque management, treatment and management of stomatitis caused by a wound, mouth exercises and massages for improving the oral functions, denture management, fluoride application, and tooth cleaning techniques (mechanical tooth cleaning). The association also organized a special committee for oral health care of the elderly. It has participated in various activities to improve the oral health of the elderly. In addition, the Korean Academy of Geriatric Dentistry established a professional course for geriatric oral health management and has provided oral health management programs. However, there are limits to providing oral health care services, as these activities of dental hygienists are not protected legally ${ }^{29)}$. Although dental hygienists have been allowed to provide oral health care after

Table 4. Employment Status of Dental Hygienists in Korea and Japan

\begin{tabular}{|c|c|c|c|c|c|}
\hline & \multicolumn{2}{|c|}{ Korea $^{\mathrm{a}}$} & \multicolumn{3}{|c|}{ Japan } \\
\hline & Workplace & Number (\%) & Workplace & Number (\%) & Clinical (\%) \\
\hline \multicolumn{6}{|c|}{ Clinical } \\
\hline & Private dental clinic ${ }^{\mathrm{b}}$ & $29,030(82.73)$ & Private dental clinic & $93,824(90.9)$ & 92.5 \\
\hline & Hospital $^{\mathrm{c}}$ & $4,877(13.90)$ & Public health center & $2,593(2.5)$ & 2.6 \\
\hline & Public health center & $1,164(3.31)$ & Hospital & $4,818(4.7)$ & 4.7 \\
\hline & & & Healthcare facility for the elderly & $244(0.2)$ & 0.2 \\
\hline \multicolumn{6}{|c|}{ Non-clinical } \\
\hline & Dental industry & $-{ }^{\mathrm{d}}$ & Dental industry & $488(0.5)$ & \\
\hline & Education-dental hygiene & $-{ }^{\mathrm{d}}$ & Education-dental hygiene & $749(0.7)$ & \\
\hline & Other & $-{ }^{\mathrm{d}}$ & Other & $464(0.5)$ & \\
\hline Total & & $35,091(100)^{\mathrm{a}}$ & & $103,180(100)$ & \\
\hline
\end{tabular}

${ }^{a}$ The number of Korean dental hygienists was investigated, based on the number of active personnel (working in the clinical field, only in the available staff, excluding fatalities, migrants and retirees) (Korean Statistical Information Service [KOSIS], 2018).

${ }^{\mathrm{b}}$ Including private clinic (20) and oriental clinic (0).

'Including dental hospital (3,492), oriental hospital (3), hospital for elderly (23) (KOSIS, 2018).

${ }^{\mathrm{d}}$ Not investigated. 
receiving brief oral health education from part-time dentists since the revision of the enforcement regulations of the Elderly Welfare Act of 2016, educating consistently and systematically the dental hygienists on oral hygiene management is difficult because of the lack of regulations regarding dental hygienists' wage ${ }^{11)}$.

Thus, a system that can conduct and manage the oral health management educations must be established to secure the roles of dental hygienists.

\section{2) Status and role of dental hygienists in Japanese long-term care facilities}

In Japan, long-term care facilities for the elderly can be divided into long-term care insurance facilities and long-term care service centers. According to Table 2, there are 13,270 long-term care insurance facilities $(959,752$ residents), 7,705 long-term care facilities for the elderly (530,280 residents), 4,241 health care facilities for the elderly (370,366 residents), 1,324 nursing home-type medical facilities (59,106 residents), and 79,114 others (hyperlocal care, community-based care, etc. ${ }^{25,26}$. According to a report on the Japanese long-term care user status in 2015 , there were $3,820,000$ and 390,000 elderly persons who used in-home care and community-based care, respect-

Table 5. The State of Long-Term Care Service of Private Dental Clinics in Japan

\begin{tabular}{cc}
\hline The state of home medical & Medical care \\
care service in dental clinics & institutions (\%) \\
\hline Total of dental clinics & $68,592(100)$ \\
Provided home medical care services & $14,069(20.5)$ \\
Home-visit dental treatment & $9,483(13.8)$ \\
Facility-visit dental treatment & $9,383(13.7)$ \\
Home-visit dental hygiene guidance & $4,597(6.7)$ \\
Home care management and guidance & $4,590(6.7)$ \\
$\quad$ (by dentist) & \\
Home care management and guidance & $3,491(5.1)$ \\
$\quad$ (by dental hygienist, etc. $^{\text {a }}$ ) & \\
Home-based preventive recuperative & $1,371(2.0)$ \\
care $^{\mathrm{b}}$ control and instruction (by dentist) & \\
Home-based preventive recuperative & $1,149(1.7)$ \\
care $^{\text {b }}$ control and instruction & \\
(by dental hygienist, etc. $^{\text {a }}$ ) & \\
Other home medical care services & $464(0.5)$ \\
\hline
\end{tabular}

${ }^{\mathrm{a}}$ Including dental technologists and dental assistants.

${ }^{b}$ Prevention of respiratory infections, improvement of feeding, swallowing function and nutrition. ively. Combined with the number of elderly persons who used long-term care insurance facilities $(n=959,725)$, the number of elderly persons who used long-term care services is approximately $5,170,000$ (Table 2$)^{25,30)}$. The number of dental hygienists who can provide professional oral hygiene care for the elderly users of long-term care insurance facilities was 0.1 per facility. Therefore, a greater number of dental hygienists were deployed in these facilities compared with Korea (Table 3) ${ }^{25,28)}$.

With its transition into an aged society in 1994, Japan started to introduce the concept of oral rehabilitation of the elderly. Following the introduction of the Regional Public Health Act in 1994, a considerable number of dental hygienists were employed at community health centers and long-term care insurance facilities for the elderly. Presently, there are 2,593 (2.5\%) and $244(0.2 \%)$ dental hygienists deployed in community health centers and long-term care facilities for the elderly, respectively $(\text { Table } 4)^{24,26)}$. Most dental hygienists work at personal dental clinics ( $n=93,824,90.9 \%)$. However, according to the Japanese statistical data for September 2014 (Table $5)^{28,31)}$, there were $14,069(20.5 \%)$ personal dental clinics that provide in-home care. In addition, dentists, dental hygienists, and other dental professionals visited patients' homes and long-term care facilities to provide dental treatment, oral hygiene care, preventive care, and education. According to the statistics released by the Japanese Ministry of Health, Labour and Welfare ${ }^{32)}$, the mean age of patients who use in-home dental care services is 69.64 years. Persons aged 80 to 89 years $(45.6 \%)$ were the most frequent users of these in-home dental care services, followed by those aged 70 to 79 years $(22.1 \%), 90$ to 99 years $(19.2 \%)$, and 60 to 69 years $(7.3 \%)$. In summary, elderly persons aged 60 years or older accounted for $94.2 \%$ of all users of in-home dental care services. Dental treatment, oral hygiene care, preventive care, education, and education for oral function recovery (oral rehabilitation) have been provided for the elderly population at the regional level. Following the introduction of the long-term care insurance system for the elderly, dental oral life care in aged society was included as a field of long-term care for the elderly. Including oral health management in the basic nursing plan can allow dental hygienists to play 
various roles from preventing respiratory infections, enhance food ingestion and deglutition function, and improve the nutritional status. The scope of their roles in society can be expanded to adapt to the changes in the population structure.

\section{3) Status and roles of dental hygienists in long-term care facilities in Korea and Japan}

The biggest difference regarding the long-term care facilities between Japan and Korea is that the former has long-term care prevention service centers (Table 2) ${ }^{25}$. In Japan, dentists or dental hygienists provide preventive oral rehabilitation and education through preventive in-home care, and preventive outpatient care, to prevent oral and nutritional diseases. A greater number of professionals were deployed in elderly care facilities in Japan; their roles were subdivided (Table 3$)^{25}$. In Korea, care workers were the most commonly deployed in elderly care facilities, with 11.67 care workers per facility. Less than one professional was deployed per facility for all other health professionals. By contrast, in Japan, care staff was the most commonly deployed in elderly care facilities at 71.5 workers per facility, followed by nursing assistant at 12.6 workers per facility and doctors at 4 workers per facility. Therefore, the number of professionals deployed in elderly care facilities was higher in Japan compared with Korea. Moreover, the roles of the health professionals deployed in elderly care facilities were more segmented in Japan compared with Korea (Table 3$)^{25,28)}$. Providing segmented care services in Japan is possible as health professionals, such as speech therapist, induction bone therapist, masseur, and long-term care specialists aside from those listed in Table 3, are also deployed in elderly care facilities.

The number of dental hygienists deployed at elderly care facilities was 0 per facility in Korea, and 0.2 per facility in Japan; therefore, a higher number of dental hygienists were deployed at elderly care facilities (Table $3)^{25,28)}$. In addition, aside from the elderly care centers with dental hygienists, $20.5 \%$ of personal dental clinics provided in-home dental care (Table 5) ${ }^{33)}$. Thus, it can be seen that dentists and dental hygienists have been actively playing their roles in providing dental treatment, oral hygiene care, preventive care, and oral rehabilitation for the elderly at the community level.

\section{Discussion}

Malignant neoplasm is the leading cause of death among the elderly in both Japan and Korea, with malignant neoplasm of the bronchial tubes and lungs being the most common. Pneumonia is the most common cause of death in elderly persons aged 65 years or older; aspiration is known as among the major risk factors of pneumonia ${ }^{34)}$. Aspiration pneumonia is an infectious disease that occurs when a foreign substance is aspirated into the airway and the lungs. Normally, foreign substances are not aspirated easily owing to the protective mechanism of the lungs. However, in persons with bronchial and muscle sensory nerves that have deteriorated due to aging, foreign substances may be aspirated and cause inflammation. Anaerobes in the normal bacterial flora of the oral cavity are the most common causative bacteria of aspiration pneumonia. They include the causative bacteria of periodontal diseases. It has been reported that $70 \%$ of elderly persons with pneumonia contract an inapparent infection that saliva or gastric juice enters their lungs and then the bacterial flora in the gastric juice or oral cavity are aspirated ${ }^{35)}$. A previous study reported that oral health management reduced the incidence of aspiration of pneumonia, verifying the importance of oral health management $^{36)}$. Issues on mental health problems due to reduced salivary secretion and lack of diet management due to aging have also been raised ${ }^{20)}$. Unhealthy oral conditions make it impossible to ingest various nutrients and place a burden on the gastrointestinal system to cause gastrointestinal diseases, which can affect mental health ${ }^{17}$. To manage the oral health of the elderly, efforts to prevent aspiration pneumonia, promote salivary secretion, and provide dietary care must be made ${ }^{37)}$. A common characteristic of population aging in Korea and Japan is that it has been occurring much faster compared with other developed countries. Because of the dramatic population aging, it has become urgent to resolve problems related to the elderly populations. In Korea, the Ministry of Health and Welfare, the Korean Academy of Geriatric Dentistry, the Korean Dentist Association, and the KDHA met in 2014 for a 
"debate on the policies for improving the oral health of the elderly in long-term care facilities" to introduce the part-time dentist employment policy for long-term care facilities for the elderly ${ }^{8)}$. With the inclusion of dentists in the enforcement regulations for the Elderly Welfare Act of 2016, it has become possible to provide dental hygiene care in long-term care facilities for the elderly ${ }^{8)}$. Public oral health policies on compulsory deployment of dental hygienists in long-term care facilities are also proposed. As the elderly care system in Korea is similar to the long-term care insurance system in Japan, efforts have been made to understand the trends in Japan as the precedent and reflect on them for continuous development. Japan emphasizes the importance of the method of oral hygiene management and prevention of aspiration pneumonia $^{22)}$. In Japan, outpatient, short-term hospitalization, and long-term hospitalization services are provided for the elderly. Outpatient services refer to the transfer of an elderly patient living at home for bathing, rehabilitative exercise, and health examination services. Short-term hospitalization provides education and training that help elderly individuals perform daily tasks over several weeks of hospitalization in a care facility. Long-term hospitalization provides management of long-term care patients. The personnel of these facilities comprise various kinds of public health workers, including dental hygienists. Dental hygienists assist elderly patients in eating and provide oral health examinations and professional oral hygiene care. They have been engaging themselves actively in these activities as they can claim payment for the tasks performed through health and long-term care insurance. Meanwhile, there is a lack of policies in the Elderly Welfare Act of 2016 that ensure dental hygienists' activities. Research on the scope of oral health services provided by dental hygienists, standard for paying dental hygienists, and the establishment of a responsibility system are needed. Ultimately, policies that ensure dental hygienists' activities must be established to improve the oral health of the elderly. The cooperation of public health workers rather than the expansion of the range of tasks of a single occupation is necessary.

\section{Acknowledgements}

We would like to express my gratitude to Professor Masaru Sugiyama from Department of Oral Health Sciences, Hiroshima University School of Dentistry, who investigated the current situation regarding dental hygienists, by visiting a university hospital, and long-term care facility in Japan. He provided valuable advice for this research. We would also like to thank Professor Koichi Kato, Dean of the Hiroshima University School of Dentistry.

\section{References}

1. He W, Goodkind D, Kowal P: An aging world: 2015 international population reports. US Department of Commerce; US Department of Health and Human Services, Washington, 2016.

2. Choi JH, Yoon HW: The changing spatial patterns of aging population in Korea. J Korean Geogr Soc 47: 359-374, 2012.

3. KOSIS: Relief expenses and aging index. Retrieved April 11, 2018, from http://kosis.kr/statHtml/statHtml.do?orgId=101\& tb1Id=DT_2KAA202_OECD\&conn_path $=\mathrm{I} 2(2017$, September 29).

4. Tavares M, Lindefjeld Calabi KA, San Martin L: Systemic diseases and oral health. Dent Clin North Am 58: 797-814, 2014. https://doi.org/10.1016/j.cden.2014.07.005

5. Fernandez-Solari J, Barrionuevo P, Mastronardi CA: Periodontal disease and its systemic associated diseases. Mediators Inflamm 2015: 153074, 2015.

https://doi.org/10.1155/2015/153074

6. KOSIS: General health checkup comprehensive assessment of dental examination by sex by age and current status of measures. Retrieved April 11, 2018, from http://kosis.kr/ statHtml/statHtml.do?orgId=350\&tblId=DT_35007_N149\& conn_path=I2(2018, February 26).

7. Lee KY, Lim SR: Effect of professional oral healthcare program on the oral status of elderly residents in long-term care facilities. J Dent Hyg Sci 16: 432-441, 2016. https://doi.org/10.17135/jdhs.2016.16.6.432

8. Ministry for Health and Welfare: Enforcement rule of the Welfare of Older Persons Act. Ordinance of the Ministry of Health and Welfare, No. 570 (Apr. 25, 2018). 
9. National Health Insurance Service: Process of long-term care insurance. Retrieved April 13, 2018, from http://www. nhic.or.kr/menu/retriveMenuSet.xx?menuId=B3000(2018, January).

10. Lee JE, Park MS: A study on an improvement plan for elderly welfare system in Korea: focusing on elderly welfare system in Germany. J Eurasian Stud 9: 379-412, 2012.

11. Kwag JM, Park II, Son MK: Suggestion for understanding and activation of the nursing home dentist system. Oral Biol Res 41: 127-133, 2017. https://doi.org/10.21851/obr.41.3.201709.127

12. Eun BJ, Kim DH, Lim JS: Trends and policy implications of nursing care insurance in Japan. J Korean Policy Stud 12: 411-432, 2012.

13. Chang SC, Kim KM: A comparative study on care insurance of Japan and long-term care insurance of Korea. Jpn Lang Lit Assoc Daehan 42: 325-345, 2009.

14. Ryu AJ: A comparative study of the most protection elderly people's support policies of the local, Korea and Japan. Korean J Care Manag 7: 105-128, 2012.

15. Cho CY, Park SA, Jung YT: The system and controversy of public long-term care insurance in Japan. GRI Rev 11: 179-206, 2009.

16. Jeon JH, Kwon JA, Nam JM, Park HB, Song YJ, Choi JS: Comparison of oral health related characteristics between a long-term patients and general population. J Korean Soc Dent Hyg 16: 11-18, 2016. https://doi.org/10.13065/jksdh.2016.16.01.11

17. Chun YH, Auh QS, Hong JP: Interrelationship between the oral disease and the systemic disease to inpatient (I). J Oral Med Pain 33: 111-120, 2008.

18. Seymour GJ, Ford PJ, Cullinan MP, Leishman S, Yamazaki $\mathrm{K}$ : Relationship between periodontal infections and systemic disease. Clin Microbiol Infect 13 Suppl 4: 3-10, 2007. https://doi.org/10.1111/j.1469-0691.2007.01798.x

19. Lee SH, Ryu JA, Yu HE, Lee JH, Shin SJ: Comparison of effects according to type of oral exercise program for elderly in Gangneung city. J Dent Hyg Sci 16: 424-431, 2016. https://doi.org/10.17135/jdhs.2016.16.6.424

20. Kim EJ, Kwag JS: Change of salivary flow rate, xerostomia, and oral health-related quality of life after oral muscle massage. J Korean Soc Dent Hyg 15: 679-685, 2015. https://doi.org/10.13065/jksdh.2015.15.04.679
21. Hwang SJ: Key food selection for assessement of oral health related quality of life among some Korean elderly. J Dent Hyg Sci 16: 361-369, 2016. https://doi.org/10.17135/jdhs.2016.16.5.361

22. Ko SM, Lim SR: Oral hygiene care for elderly in care facility. J Korean Dent Assoc 53: 678-687, 2015.

23. Yoneyama T, Yoshida M, Sasaki H, et al.: A study for the effects of oral health care on the prevention of aspiration pneumonia in the compromised elderly patients. J Jpn Assoc Dent Sci 20: 58-68, 2001.

24. KOSIS: Classification of personnel status II (nurses and others). Retrieved April 11, 2018, from http://kosis.kr/ statHtml/statHtml.do?orgId=354\&tblId=DT_HIRA4A\&con n_path=I2(2018, April 5).

25. Ministry of Health, Labour and Welfare: Elderly care facilities in Japan. Retrieved April 11, 2018, from http://www.mhlw.go.jp/toukei_hakusho(2015, April 30).

26. Ministry of Health, Labour and Welfare: Increase in number of persons who are eligible for LTC insurance and users. Retrieved April 11, 2018, from http://www.mhlw.go.jp/ english/policy/care-welfare/care-welfare-elderly/d1/ltcisj_e.p df(2015, April 30).

27. KOSIS: Status of long-term care institutions by type of salary by year, city, and province. Retrieved April 13, 2018, from http://kosis.kr/statHtml/statHtml.do?orgId=350\&tblId=DT_ 35006_N019\&conn_path=I2(2017, November 20).

28. KOSIS: Status of specialist in long-term care facilities by city, county, and county. Retrieved April 11, 2018, from http://kosis.kr/statHtml/statHtml.do?orgId=350\&tblId=DT_ 35006_N022\&conn_path=I2(2017, November 10).

29. Moon YM, Bae SS, Moon HY: Some elderly care facilities workers' oral health awareness, knowledge, behavior and education needs. J Korean Entertain Ind Assoc 9: 277-285, 2015. https://doi.org/10.21184/jkeia.2015.03.9.1.277

30. Japan Dental Hygienists' Association: An expanding workplace. Retrieved April 11, 2018, from https://www.jdha.or. jp/ english/index.html.

31. Ministry of Health, Labour and Welfare: Survey of medical institutions. Retrieved April 11, 2018, from http://www. mhlw.go.jp/english/database/db-hss/dl/Survey_of_Medical_I nstitutions_2014.pdf(2014, October 1).

32. Ministry of Health, Labour and Welfare: Mean age of patients who use in-home dental care services in Japan. 
Retrieved April 11, 2018, from http://www.mhlw.go.jp/ toukei/list/zaitakushika_c.html (2015, April 30).

33. Ministry of Health, Labour and Welfare: State of home medical care services. Retrieved April 11, 2018, from http://www.mhlw.go.jp/english/database/db-hss/dl/Survey_o f_Medical_Institutions_2014.pdf(2014, September 10).

34. Stupka JE, Mortensen EM, Anzueto A, Restrepo MI: Community-acquired pneumonia in elderly patients. Aging Health 5: 763-774, 2009. https://doi.org/10.2217/ahe.09.74

35. Kim KW, Yoon HJ, Kim MR, Lee HK, Lee KS: Effects of oral hygiene improvement of the elderly patients by caregiver's in rural long-term care hospital. J Agric Med Commun Health 35: 13-20, 2010.

https://doi.org/10.5393/JAMCH.2010.35.1.013

36. Scannapieco FA, Shay K: Oral health disparities in older adults: oral bacteria, inflammation, and aspiration pneumonia. Dent Clin North Am 58: 771-782, 2014.

https://doi.org/10.1016/j.cden.2014.06.005

37. Yang SB, Moon HS, Han DH, Lee HY, Chung MK: Oral health status and treatment need of institutionalized elderly patients. J Korean Acad Prosthodont 46: 455-469, 2008. https://doi.org/10.4047/jkap.2008.46.5.455 